\title{
Evaluating Sustainability of Truck Weight Regulations: A System Dynamics View
}

\author{
Pei $\mathrm{Liu}^{1,2}$, Dong $\mathrm{Mu}^{1}$ \\ ${ }^{1}$ School of Economics and Management, Beijing Jiaotong University, ${ }^{2}$ School of Business, Shandong University at \\ Weibai (China) \\ liupeisdu@yahoo.com, mudong bjtu@yahoo.com
}

Received: July 2015

Accepted: December 2015

\section{Abstract:}

Purpose: Targeting the problem of overloaded trucking regarding the Highway Transportation of iron ore from Caofeidian to Tangshan (HTCT), this paper aims to assess the long-term effects of alternative Truck Weight Regulation (TWR) policies on the sustainability of the HTCT.

Design/methodology/approach: This paper develops a model for policy evaluation using System Dynamics (SD). The model, comprising six interrelated modules, is capable of simulating the effects of TWR policies on trucking issues, such as freight flow, truck traffic flow, pavement performance, highway transport capacity and trucking time. The model further sheds light on the Cumulative Economic Cost (CEC), including the transport cost and time cost of freight owners, and the Cumulative Social Cost (CSC), including the pavement maintenance cost, greenhouse gas emission cost, atmospheric pollutants emission cost and traffic accidents cost, so the effects of TWR policies on the sustainability of the HTCT could be evaluated.

Findings: According to the different values of the overload ratio that are allowed by policy, alternative TWR policies are classified into three types, which are The Rigid Policy (TRP), The Moderate Policy (TMP) and The Tolerant Policy (TTP). The results show that the best policy for the sustainability of the HTCT depends on the relative importance of CSC, which is 
expected by the local government. To be specific, (1) if CSC is considered to be much less important than CEC, the local government should continue implementing TTP with the maximum overload ratio; (2) if CSC is considered to be much more important than CEC, then TRP is recommended; and (3) if CSC is considered to be slightly more important than CEC, TMP with an overload ratio of $80 \%$ is best.

Practical implications: The conclusions of this paper may help the local government design appropriate TWR policies to achieve the sustainability of the HTCT.

Originality/value: To the best of our knowledge, this is the first effort to evaluate TWR policies on the sustainability of the highway freight system based on SD.

Keywords: overweight transportation, sustainability, freight transportation, system dynamics

\section{Introduction}

Sustainability has become a major issue that almost all industries must consider (Fiksel, 2006). Sustainable transportation is the achievement of continued transportation activities supported by environmental, economic and social objectives at various space-based scales of operation (Tao \& Hung, 2003). Freight transportation, particularly heavy-duty trucking, is a major source of environmental burden. In China, up to $75 \%$ of freight is transported over highways (National Bureau of Statistics PRC, 2013). A common problem of freight highway transportation in China is overloaded trucking, which has significant influences on both economic aspects, including transport cost and time cost of freight owners, and social aspects, such as infrastructure, Greenhouse gas and Atmospheric pollutants Emission (GAE) and traffic safety. In 2004, the Chinese government launched a nationwide enforcement activity against overweight vehicles (Hang \& Li, 2010). Although the effects of Truck Weight Regulation (TWR) on transport cost (Xu, 2008) and infrastructure (Hang \& Li, 2010; Khan, Ayub \& Qadir, 2014) are definite, the influences of TWR on the environment, traffic safety and the sustainability of highway freight systems remain unclear. Thus, it is important to develop a model to evaluate the long-term sustainable effects of TWR and to enact effective policies to achieve the sustainability of highway freight systems.

For the evaluation of sustainable transportation policy, an important research priority is the development of modeling and decision-making approaches from the system perspective (Ülengin, Kabak, Önsel, Ülengin \& Aktaş, 2010; Fiksel, 2006), which focuses on interrelationships among components of the transportation system and treats the system's evolution as the result of interactions and feedbacks among those components. System Dynamics (SD), which was initially developed by Forrester from MIT in the 1950-1960s, is an 
appropriate tool for modeling complex systems, such as transportation systems, that involve a number of different stakeholders or agents and result in complex interrelationships and feedbacks within the systems (Shepherd, 2014). Thus, SD is well suited for supporting the policy analysis and decision-making of transportation systems for long-term horizons (Abbas \& Bell, 1994).

The application of system dynamics for transportation modeling was first found in the 1990s, and work has continued into the 2000s. Abbas and Bell (1994) first discussed the applicability of system dynamics for transportation modeling and listed twelve advantages of the approach compared to traditional transport modeling. Piattelli, Cuneo, Bianchi and Soncin (2002) built an SD model of a multimodal freight system of Germany and then simulated the effects of a carbon tax and infrastructure investment on the mode shares of the system. Han and Hayashi (2008) established an SD model of an inter-city passenger transportation system in China and then designed $\mathrm{CO} 2$ mitigation policies by sensitivity analysis. There is additional research that treats transportation as a sub-system of a socio-economic system, establishing SD models that reflect interrelationships among transportation, population, employment and land use and evaluating the effects of alternative policies (Fiorello, Martino \& Rinaldi, 2002; Haghani, Lee \& Byun, 2003; Pfaffenbichler, Emberger \& Shepherd, 2010; Fiorello, Fermi \& Bielanska, 2010; Pfaffenbichler, 2011; Dou, Li, Li \& Gou, 2014).

However, the above research does not cover the issue of overloaded trucking, which has a significant influence on the distribution of interests among stakeholders within a transportation system. For example, overloaded trucking enhances scale economies and distributes more profit to freight owners and carriers, but these profits come at the expense of the government and the public because it greatly damages the infrastructure and worsens traffic safety. Considering that overloaded trucking is very common in China, it cannot be neglected when modeling highway freight systems in China. However, there is very little literature regarding SD models that considers overloaded trucking. Hang and $\mathrm{Li}$ (2010) built an SD model of overloaded trucking in Anhui Province, China. Their model evaluates three types of TWR policies: the rigid policy (in which the truck weight meets the Chinese statutory limit), the moderate policy (in which the truck weight exceeds the statutory limit to a moderate degree) and the tolerant policy (in which the local government acquiesces to highly overweight truck loads). The results show that the moderate policy is the most appropriate option to reduce the system's cost, which includes the transport cost and pavement maintenance cost. However, they did not further consider TWR effects on transport time and the time cost of freight owners caused by traffic congestion. They also did not consider TWR's impact on the environment and the sustainability of the system. The above issues caused by overloaded trucking can be classified into two categories: economic issues, including transport cost and transport time, which are of concern to freight owners and carriers, and social issues, including pavement conditions, GAE and traffic safety, which are of concern to the government and the public. When trucks are overloaded, both economic issues and social issues vary simultaneously. 
Therefore, if all of these issues are considered, the best TWR policy may be different from that of Hang and Li (2010).

The aim of this paper is to establish an SD model of a highway freight system, considering two types of the system's costs: economic costs, which correspondingly address economic issues, and social costs, which correspondingly address social issues, to evaluate the long-term effects of alternative TWR policies on the sustainability of the system. The remainder of the paper is organized as follows: Section 2 introduces the SD model, including the model framework and model development; Section 3 provides model validation; Section 4 presents the results and discussions; and Section 5 presents the conclusions.

\section{Model Development}

The SD model is based on the case of the Highway Transportation of iron ore from Caofeidian to Tangshan (HTCT) in Hebei Province, which is a typical case of overloaded bulk freight trucking in China, as the truck type, highway types and highway configuration involved in this case are commonly adopted by other regions of China. Therefore, there is a certain general applicability of this case.

\subsection{The Case Description}

The case of the HTCT is shown in Figure 1. Caofeidian port is the largest unloading port of iron ore in northern China. In the vicinity is Tangshan, the largest steel industry base of China, which has a high demand for iron ore. Currently, all of the iron ore is transported over two highways. One of them is an enclosed express highway, marked as \#1 in Figure 1, which is equipped with toll stations that charge the passing freight vehicles by weight. Due to the high rate of the weight charge on overloaded vehicles, the express highway has deterred all of the overloaded vehicles and is only used by a small number of trucks that meet the statutory limit (55 tons of gross weight with 35 tons of load weight, with the corresponding overload ratio being zero). The other highway, marked as \#2, is a regular highway that is open to all vehicles and is free of charge, with traffic police performing random inspections during the day. Therefore, most of the trucks choose to use this regular highway during the night when the traffic police are off duty. These trucks with highly overweight loads (113 tons of gross weight with 93 tons of load weight, with the corresponding overload ratio being 166\%) cause severe damage to the pavement. In this study, an SD model was built to produce effective policies to achieve sustainable development of the HTCT for the next ten years. 


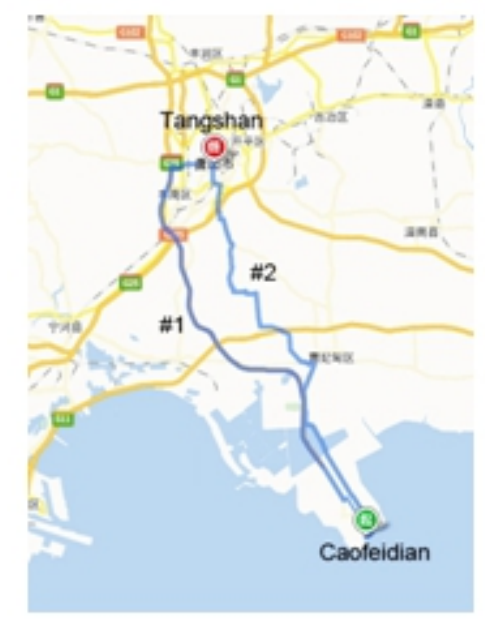

Figure 1. The HTCT

\subsection{Hypotheses of the Model}

Based on the case description and aims of this research, the following assumptions have been adopted:

- The model only considers the trucking process from Caofeidian to Tangshan. Other processes, such as iron ore unloading from ships in Caofeidian port, storage and truck loading in the port yard, and truck unloading at the destination steel companies, are not included.

- For the convenience of obtaining the average transport mileage from the Caofeidian port to the steel companies in Tangshan, a circular area that covers all of these companies is defined, with the destination at its center. The freight volume of the HTCT is the total demand of these companies, which means that the model operates at the aggregate level.

- The truck type used in the model is the SD123 (Semi-trailer Diesel truck with 1 steer axle, 2 driving axles and 3 rear axles). Other truck types are excluded because the SD123 trucks compose the vast majority of trucks used in the HTCT.

- The model considers only pavement damage from heavy-duty trucks. Additionally, it is assumed that pavement maintenance is performed at the end of the year and can be accomplished within the year. 


\subsection{Model Framework}

The SD model of the HTCT comprises six interconnecting modules, with each module focusing on one specific function, as is shown in Figure 2. Among these modules, the freight generation module, speed-flow module and modal split module are developed on the basis of the classic four steps model of freight transportation (De Jong, Gunn \& Walker, 2004). The pavement maintenance module predicts pavement maintenance operations and provides a Pavement Performance Indicator (PPI) for the calculation of the highway transport capacity in the highway transport capacity module, and then, the average transport time can be further obtained in the speed-flow module. Finally, in the policy evaluation module, social costs, including the pavement maintenance cost, traffic accidents cost and GAE cost, are calculated. The TWR policies are then evaluated together with the economic costs, including the transport cost and time cost that are calculated in the modal split module.

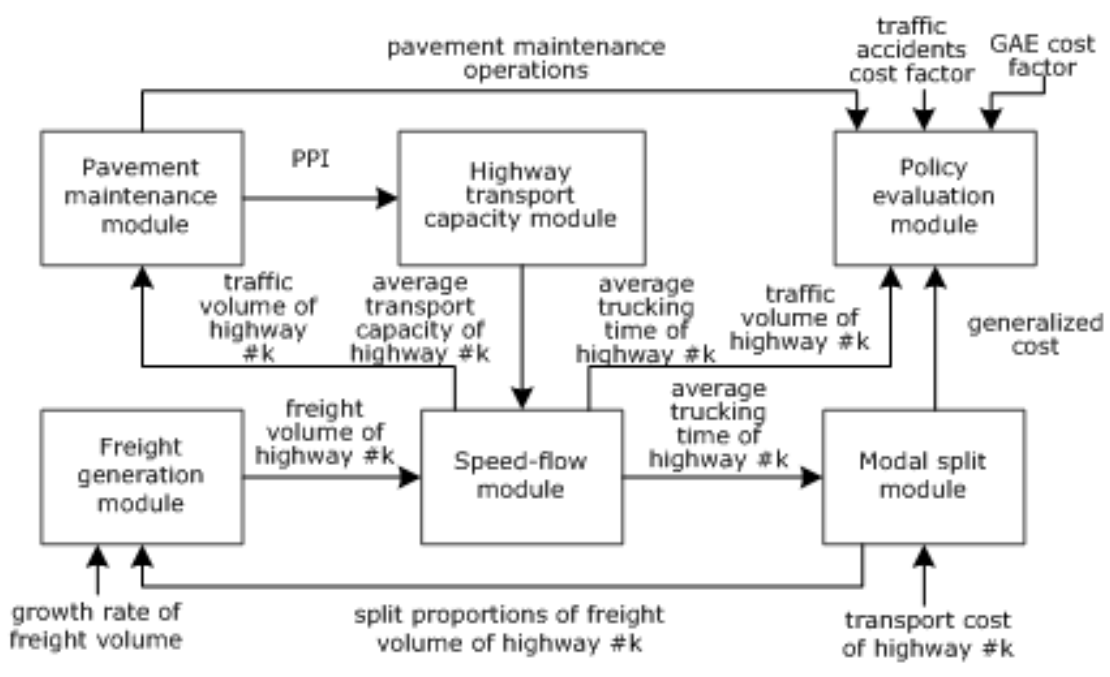

Figure 2. Framework of the SD model

\subsection{Model Development}

\subsubsection{Freight Generation Module}

The function of this module is to forecast the freight volume of the HTCT first and then distribute it to two highways according to the split proportions of the freight volume of the two highways, which are provided by the modal split module. The freight volume of the HTCT is forecast exogenously by referring to the results of Gao (2012), who forecasts the freight volume of iron ore from Caofeidian to Tangshan by estimating the production capacity of the steel industry in Tangshan. 


\subsubsection{Pavement Maintenance Module}

Trucks, particularly overloaded trucks, cause damage to the highway pavement and lower pavement performance. This module predicts pavement maintenance operations by the highway operator according to PPI, which is defined by the Specifications for Design of Highway Asphalt Pavement (SDHAP) published by the Ministry of Transport of China. The PPI value of highway \#k $(k=1,2)$, ranging from zero (when the pavement condition is at its worst) to 100 (when the pavement condition is at its best), is calculated by the following function (Sun \& Liu, 1995):

$$
P P I_{t}^{k}=P P I_{t-1}^{* k *}\left(1-e^{-a^{k \beta} k}\right)
$$

where $P P I_{t}^{k}$ represents the PPI value of highway \#k in year $t$ before pavement maintenance, $P P I_{t-1}^{* k}$ is the PPI value in year $t-1$ after pavement maintenance, and $a^{k}$ and $\beta^{k}$ are related to the actual service life of highway \#k, which is calculated according to the equivalent axles of certain truck traffic with a certain freight load and the maximum cumulative equivalent axles that the highway can bear.

By the value of $P P I_{t}^{k}$ and performance thresholds of the maintenance operations defined by SDHAP, the pavement maintenance operation in year $t$ can be determined. There are three types of maintenance operations performed by the highway operator of the HTCT, which are Do Nothing (DN), Corrective Maintenance (CM) and Restorative Maintenance (RM). The performance thresholds and maintenance effects of these maintenance operations are shown in Table 1.

\begin{tabular}{|c|c|c|}
\hline Maintenance operations & $\begin{array}{l}\text { Performance thresholds of } \\
\text { maintenance }\end{array}$ & Maintenance effects \\
\hline RM & $P P I_{t}^{k} \leq 45, k=1,2$ & $P P I_{t}^{* 1}=100, P P I_{t}^{* 2}=100$ \\
\hline CM & $45<P P I_{t}^{k} \leq 55, k=1,2$ & $P P I_{t}^{* 1}=85, P P I_{t}^{* 2}=80$ \\
\hline DN & $P P I_{t}^{k} \geq 55, k=1,2$ & - \\
\hline
\end{tabular}

Table 1. Pavement maintenance operations and maintenance effects

In addition, the maintenance interval is set as once a year at most due to limited maintenance investment and human resources.

\subsubsection{Highway Transport Capacity Module}

This module is for calculating the average transport capacity of highway \#k. Because highway transport capacity is directly related to PPI, the average transport capacity of highway \# $k$ can be calculated by the following function: 


$$
C_{t}^{k}=C^{k *} \frac{\left(P P I_{t}^{k}+P P I_{t-1}^{* k}\right) / 2}{100}
$$

where $c^{k}$ is the maximum transport capacity of highway \#k that is obtained from SDHAP, $\left(P P I_{t}^{k}+P P I_{t-1}^{* k}\right) / 2$ is approximately the average value of PPI in year $t$, and $c_{t}^{k}$ is correspondingly the average transport capacity of highway $\# k$ in year $t$.

The unit of $c^{k}$ is defined by SDHAP as Passenger Car Unit (PCU) per lane per hour, and the value varies with the highest speed of the truck. Therefore, in the case of the HTCT, $c^{k}$ is determined by the number of lanes, the time window in which trucks use the highway and the highest speed of trucks with a certain freight load. In the meantime, transport mileage should also be considered, so the unit of $c^{k}$ as well as $c_{t}^{k}$ employed in the model is PCU* km.

\subsubsection{Speed-Flow Module}

The function of this module is to calculate the average trucking time on highway \# $k$ using the average transport capacity of highway $\# k$, which is fed by the highway transport capacity module, and the freight volume of highway $\# k$, which is fed by the freight generation module. The calculation process involves two steps:

- Predicting the average transport speed by applying the following speed-flow function (Wang, 2003):

$$
\left\{\begin{array}{l}
s_{t}^{k}=\frac{\lambda^{k *} S^{k}}{1+\left(v_{t}^{k} / c_{t}^{k}\right)^{b_{t}}} \\
b_{t}=w^{k}+\mu^{k *}\left(v_{t}^{k} / c_{t}^{k}\right)^{3}
\end{array}\right.
$$

where $s_{t}^{k}$ and $s^{k}$ are the average speed and highest speed of trucks on highway \#k, $s_{t}^{k}$ is the average transport capacity of highway \#k in year $t$, and $v_{t}^{k}$ is the truck traffic volume of highway \#k in year $t$, which is converted from the freight volume of the highway. The values of $\lambda^{k}, w^{k}$ and $\mu^{k}$ are defined by SDHAP.

- Calculating the average trucking time on highway \#k according to highway mileage.

\subsubsection{Modal Split Module}

The function of this module is to calculate the split proportion of the freight volume of each highway by applying the logit model (Fiorello et al., 2002), which is in form of: 


$$
p_{t}^{k}=\frac{e^{-\theta^{*} u_{t}^{k}}}{\sum_{k} e^{-\theta^{*} u_{t}^{k}}}
$$

where $p_{t}^{k}$ is the split proportion of the freight volume of highway \#k in year $t, \theta$ is the spread parameter, $u_{t}^{k}$ is the negative utility of trucking on highway \#k. It is assumed here tha $u_{t}^{k}$ includes only trucking generalized cost, namely,

$$
u_{t}^{k}=g c_{t}^{k}=t c_{t}^{k}+t_{t}^{k *} V O T_{t}
$$

where $g c_{t}^{k}$ is the generalized cost of trucking on highway \#k in year $t$, including transport cost $t c_{t}^{k}$ and time cost $t_{t}^{k *} V O T_{t}$. Here, $t_{t}^{k}$ is the transport time of the unit freight volume provided by the speed-flow module, and $V O T_{t}$ is the value of time of iron ore. $t c_{t}^{k}$ is the transport cost of the unit freight volume, which varies with the truck load. The higher the truck load, the lower the $t c_{t}^{k}$. Xu (2008) has given $t c_{t}^{k}$, as a function of the truck load in China in the starting year:

$$
t c_{0}^{k}=2.5146^{*} x^{-0.647 *} m^{k}+g^{k}
$$

where $x$ is the truck load, $g^{k}$ is the toll of trucking on highway $\# k$, and $m^{k}$ is the mileage of highway \#k.

\subsubsection{Policy Evaluation Module}

This module functions to evaluate alternative TWR policies according to the Cumulative Economic Cost (CEC) and Cumulative Social Cost (CSC) within the simulation period. In the model, economic costs, namely, the transport cost and time cost of year $t$, have been calculated in the modal split module. Social costs of year $t$ include the following:

- Pavement maintenance cost. This is calculated according to the pavement maintenance operations, provided by the pavement maintenance module, and the corresponding maintenance cost obtained from an onsite survey of the highway operator. The annual growth rate of the pavement maintenance cost is also considered.

- Traffic accidents cost. This is calculated by multiplying the freight volume of highway $\# k$, the transport mileage and a traffic accidents cost factor ( $\mathrm{Li}, 2013)$. The traffic accidents cost factor, which represents the traffic accidents cost of unit ton*km, is related to the truck load, which means the higher the truck load, the higher the accident rate and the greater the factor value. The annual growth rate of the traffic accidents cost is considered as well.

- Greenhouse gas emission cost. This is obtained by multiplying the diesel consumption of trucks, the carbon emission factor of diesel and the price of carbon trading (Maurer, 
2008). The diesel consumption of trucks is calculated by multiplying the truck traffic volume, the average trucking time, and the diesel consumption per vehicle per hour, in which the variation of fuel consumption under different truck weights is considered. In addition, fuel efficiency improvements for heavy-duty trucks are also taken into account (De Ceuster, Van Herbruggen, Logghe \& Proost, 2004).

- Atmospheric pollutants (including CO, HC, NOx and PM) emission cost. This is obtained by multiplying the emission amount of atmospheric pollutants and the marginal cost of emission ( $\mathrm{Li}, 2013$ ). The emission amount of atmospheric pollutants is calculated in a different way from that of greenhouse gas emission because the atmospheric pollutants emission factor, defined by the National Third Phase Motor Vehicle Pollutants Emission Standard of China, is in units of ton/( $\mathrm{km}^{*}$ hour). Thus, it is calculated by multiplying the transport mileage, total transport time of truck traffic and the atmospheric pollutants emission factor. Moreover, the variation of atmospheric pollutants emission under various truck loads is also considered by introducing a correction factor.

\section{Model Validation}

\subsection{Data Acquisition and the Key Parameters of the Model}

The model is based on both primary data and secondary existing data. Primary data is obtained from an onsite survey of the highway operator and truck drivers as well as an investigation by China Highway Consultants Co., Ltd, a partner working on this research project. Secondary data is obtained from the peer-reviewed literature, the China Transport Statistical Yearbook and SDHAP. Based on the above data, some of the key parameters of the model are shown in Table 2.

\begin{tabular}{|c|c|c|}
\hline Parameters & Values & Units \\
\hline Initial value of freight volume of the HTCT & $9,366,000$ & ton \\
\hline Initial value of freight volume of the express highway & $1,870,000$ & ton \\
\hline Initial value of freight volume of the regular highway & $7,490,000$ & ton \\
\hline Growth rate of freight volume of the HTCT & $\begin{array}{r}4.129 \%, 2015-2019 \\
2.919 \%, 2020-2024\end{array}$ & $\begin{array}{c}\text { Dmnl } \\
\text { (Dimensionless) }\end{array}$ \\
\hline Maximum cumulative equivalent axles of the express highway & $42,180,000$ & times \\
\hline Maximum cumulative equivalent axles of the regular highway & $33,000,000$ & times \\
\hline Maximum transport capacity of the express highway & $734,670,000$ & PCU*km/Year \\
\hline PCU of the truck on the express highway & 7.0 & PCU/vehicle \\
\hline PCU of the truck on the regular highway & 5.5 & PCU/vehicle \\
\hline Mileage of the express highway & 90.7 & $\mathrm{~km}$ \\
\hline Mileage of the regular highway & 94.9 & $\mathrm{~km}$ \\
\hline Value of time of iron ore & 70 & Yuan/hour \\
\hline Annual growth rate of transport cost & $2.84 \%$ & Dmnl \\
\hline Annual growth rate of pavement maintenance cost & $10.02 \%$ & Dmnl \\
\hline Annual growth rate of traffic accidents cost & $6.72 \%$ & Dmnl \\
\hline Carbon emission factor of diesel & 3.16 & ton/ton \\
\hline Price of carbon trading & 120 & Yuan/ton \\
\hline
\end{tabular}

Table 2. The key parameters used in the model 


\subsection{Model Validation}

The stock flow diagram of the model was developed using the Vensim (Ventana Systems, Inc.) software package, with functions and parameters transformed into model equations. After the model was developed, simulation runs were first conducted on historical years for model validation. The starting year is 2008, when Caofeidian port was first operated. Simulation outputs of two variables, which are the maintenance operations of the regular highway and the average transport time of a single truck using the regular highway, were compared with the actual values over the same period, and there are satisfying correlations between the simulated values and the actual values for both variables, as shown in Figure 3 and Figure 4. The validation process was then undertaken for other variables, and the results are also well correlated with the actual values.

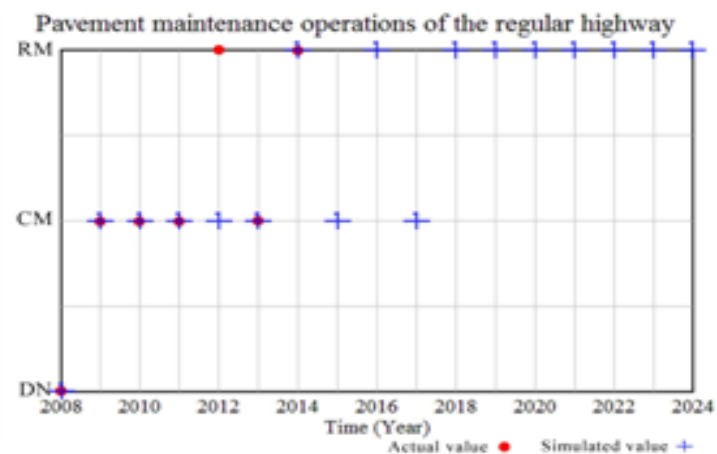

Figure 3. Model validation on the pavement maintenance operations of the regular highway

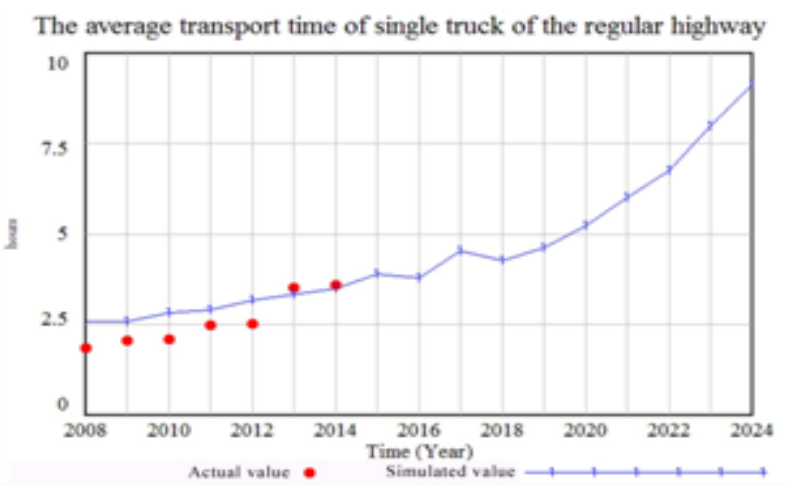

Figure 4. Model validation on the average transport time of a single truck using the regular highway

\section{Results and Discussions}

By setting different values of the overload ratio of trucks, alternative TWR policies were simulated and the effects on the sustainability of the HTCT over the next ten years were evaluated. First, a reference scenario was built to simulate the current practice of overloaded 
trucking in the HTCT. As mentioned above, there is severely overloaded trucking on the regular highway, with an average truck load of 93 tons and a corresponding overload ratio of $166 \%$. It is assumed that this value is the maximum overload ratio of the truck. Then, other policy scenarios with different overload ratios were simulated and compared to the reference scenario. Referring to the definitions of TWR policies by Hang and Li (2010), three types of TWR policies were introduced, for which the overload ratios ranged from zero to $166 \%$, as follows:

- The Rigid Policy (TRP), where the overload ratio is zero;

- The Moderate Policy (TMP), where the overload ratio is not higher than $100 \%$; and

- The Tolerant Policy (TTP), where the overload ratio is greater than $100 \%$ until reaching the maximum value of $166 \%$.

The effects of the above TWR policies are as follows.

\subsection{Effects of TRP}

In this policy scenario, it is assumed that the local government would implement TRP, which would require all of the overloaded trucks on the regular highway to meet the statutory limit. The results show that the sustainable effects of TRP are as follows:

- TRP causes an increase of CEC by 5.475 billion Yuan compared to the reference scenario because:

- the cumulative transport costs of both highways increase since limiting vehicle loads counteracts the scale economies of transportation;

- the cumulative time cost of the express highway grows, because the regular highway is less attractive after implementation of TRP and more trucks are directed to the express highway, causing congestion and leading to both a higher average transport time of a single truck (as shown in Figure 5) and a greater total transport time of truck traffic (as shown in Figure 6); and 


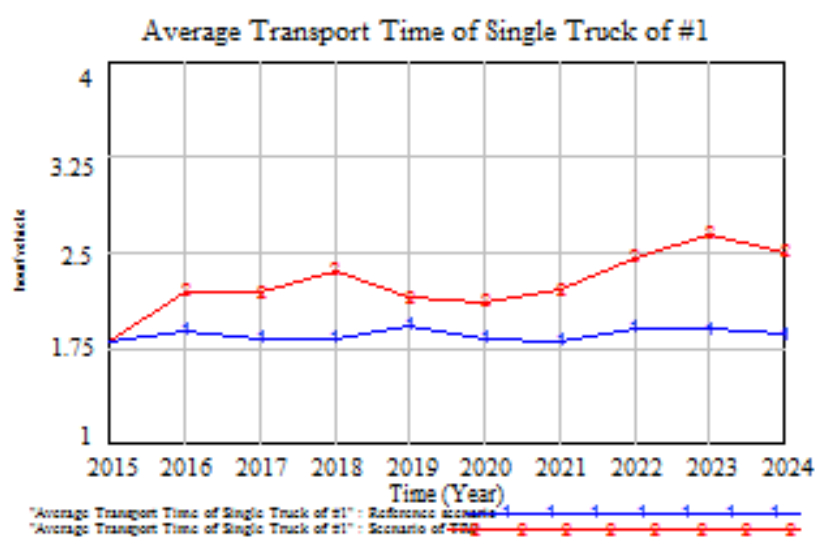

Figure 5. TRP effects on the average transport time of a single truck using the express highway

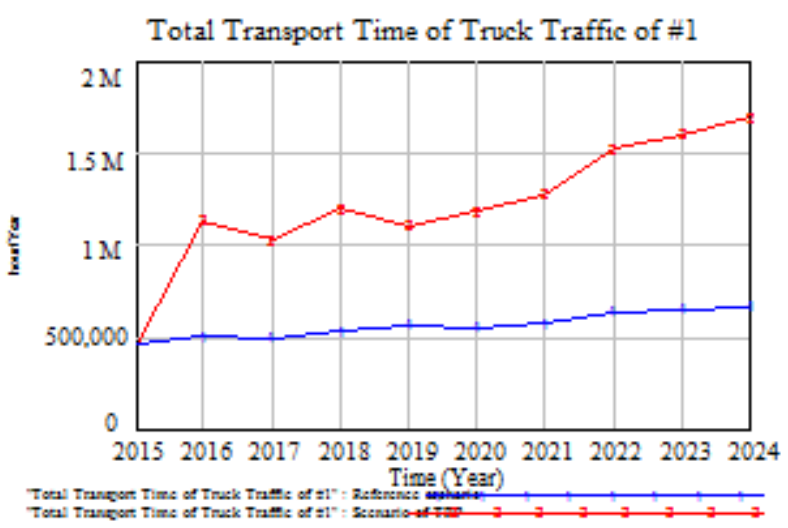

Figure 6. TRP effects on the total transport time of truck traffic on the express highway

- the cumulative time cost of the regular highway rises as well because although the average transport time of a single truck decreases (as shown in Figure 7) as the result of a greater highway transport capacity caused by an enlarged trucking time window after implementation of TRP (namely, the trucking time is no longer limited to the nighttime under TRP), TRP still gives rise to a higher truck traffic volume on the regular highway despite a lower split proportion of freight volume and leads to a higher total transport time of truck traffic in most years of the simulation period (as shown in Figure 8 ), which causes the cumulative time cost of the regular highway to rise. 


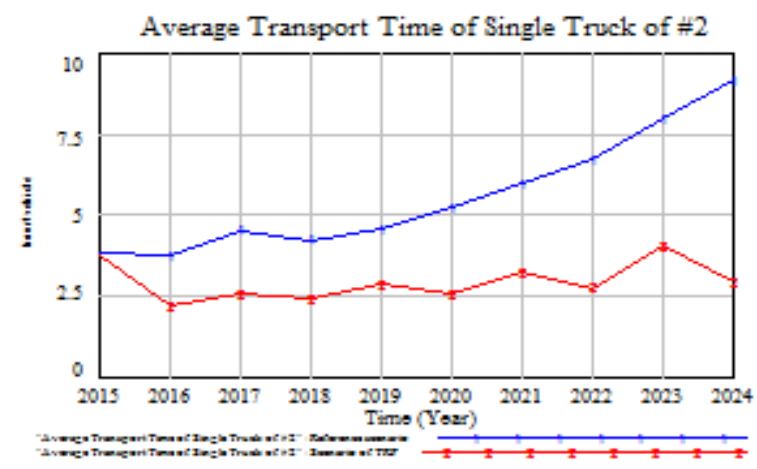

Figure 7. TRP effects on the average transport time of a single truck using the regular highway

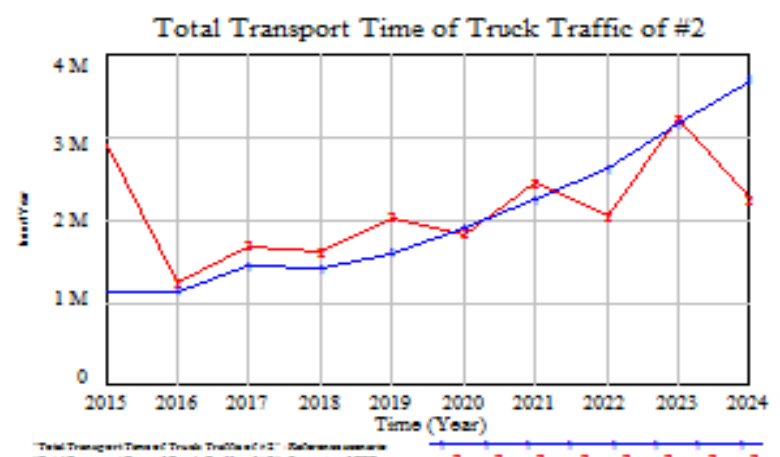

Figure 8. TRP effects on the total transport time of truck traffic on the regular highway

- TRP causes a decrease of CSC by 3.717 billion Yuan compared to the reference scenario because:

- the cumulative pavement maintenance cost decreases by 3.23 billion Yuan because TRP greatly protects the pavement of the regular highway and reduces operation times of pavement maintenance, particularly costly Restorative Maintenance (RM), as is shown in Figure 9;

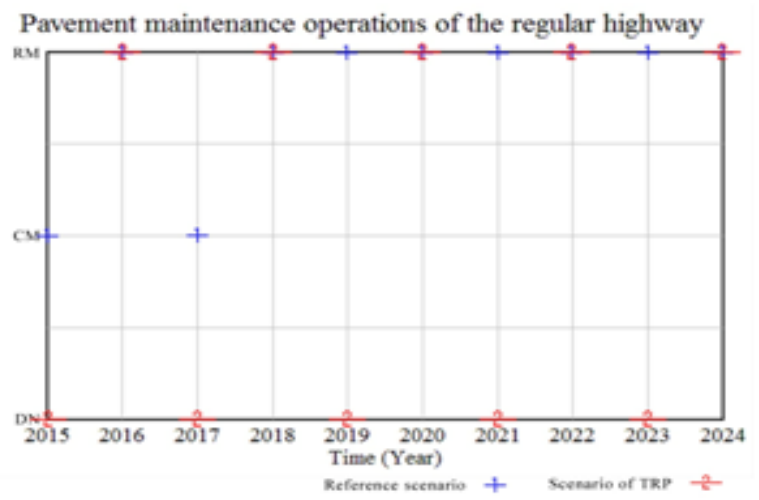

Figure 9. TRP effects on the pavement maintenance operations of the regular highway 
- the cumulative GAE cost increases by 0.072 billion Yuan because although GAE of a single truck decreases under a lighter load, the cumulative amount of GAE increases as the result of the greater truck traffic volume for both highways; and

- the cumulative traffic accidents cost decreases by 0.558 billion Yuan because the decreased traffic accidents rate under TRP contributes more than the increased traffic volume by TRP.

- In summary, the increase of CEC is higher than the decrease of CSC by TRP, which results in an increase of the cumulative cost of the HTCT by 1.758 billion Yuan compared to the reference scenario.

\subsection{Effects of TMPs and TTPs}

As the overload ratio increases (with an increment that is set as $10 \%$ ), TMPs and TTPs were evaluated. It is found that:

- As the overload ratio increases, the cumulative generalized cost and the cumulative GAE cost decrease, while the cumulative traffic accidents cost keeps growing.

- The cumulative pavement maintenance cost first declines as the overload ratio increases and reaches the lowest value when the overload ratio is $50 \%$ and then rises as the overload ratio continues to grow. This is because overloaded trucking gives rise to both equivalent axles of a single truck increasing and truck traffic volume decreasing. When the overload ratio is $50 \%$, the cumulative equivalent axles of truck traffic are the lowest, which means the pavement damage of truck traffic is at a minimum.

- Summing the above costs and considering the results of TRP, the cumulative cost of the HTCT reaches the lowest value at an overload ratio of $130 \%$, which indicates that if the cumulative cost of the HTCT is taken as the evaluation criterion, the best policy for the sustainability of the HTCT is TTP with an overload ratio of $130 \%$.

\subsection{The Best Policies under the Varying Relative Importance of CSC}

In the practice of decision-making, the varying relative importance of CSC and CEC may be considered by the local government, which means that different weights of CSC and CEC may be imposed on the evaluation criterion, which is in form of:

$$
w C c=a^{*} \csc +(1-a)^{*} \operatorname{cec}
$$


where wcc is the weighted cumulative cost of the HTCT, comprising the weighted CSC and the weighted CEC. $a$ is the weight of CSC, ranging from zero (least important) to 1 (most important). Then, under various weights of CSC, the minimum values of wcc of alternative TWR policies were found, and the corresponding TWR policies are the best policies for the sustainability of the HTCT, which are shown by shaded boxes in Table 3.

\begin{tabular}{|c|c|c|c|c|c|c|c|c|c|c|c|c|}
\hline \multirow{2}{*}{\multicolumn{2}{|c|}{$\begin{array}{c}\text { Weight value of CSC } \\
\text { Importance of CSC } \\
\text { compared to CEC }\end{array}$}} & 0 & 0.1 & 0.2 & 0.3 & 0.4 & \multirow{2}{*}{$\begin{array}{c}0.5 \\
\text { Equally } \\
\text { important }\end{array}$} & 0.6 & 0.7 & 0.8 & 0.9 & 1 \\
\hline & & \multicolumn{3}{|c|}{ Very unimportant } & \multicolumn{2}{|c|}{ Unimportant } & & \multicolumn{2}{|c|}{ Important } & \multicolumn{3}{|c|}{ Very important } \\
\hline \multirow{17}{*}{$\begin{array}{l}\text { TWR } \\
\text { policies } \\
\text { (overload } \\
\text { ratio) }\end{array}$} & $\operatorname{TRP}(0)$ & 16.67 & 15.45 & 14.23 & 13.00 & 11.78 & 10.56 & 9.33 & 8.11 & 6.88 & 5.66 & 4.44 \\
\hline & TMP (10\%) & 17.93 & & 15.45 & & 12.96 & 11.72 & 10.48 & 9.24 & 8.00 & 6.76 & 5.52 \\
\hline & TMP (20\%) & 17.22 & 16.04 & 14.86 & 13.68 & 12.50 & 11.32 & 10.13 & 8.95 & 7.77 & .59 & 5.41 \\
\hline & TMP (30\%) & 16.65 & 15.51 & 14.36 & 13.22 & 12.07 & 10.93 & 9.78 & 8.64 & 7.49 & 6.35 & 5.20 \\
\hline & TMP (40\%) & 16.12 & 15.03 & 13.94 & 12.84 & 11.75 & 10.65 & 9.56 & 8.47 & 7.37 & 6.28 & 5.18 \\
\hline & TMP (50\%) & 15.72 & 14.63 & 13.54 & 12.45 & 11.36 & 10.27 & 9.18 & 8.09 & 7.00 & 5.91 & 4.82 \\
\hline & TMP $(60 \%)$ & 15.08 & 14.12 & 13.16 & 12.20 & 11.24 & 10.28 & 9.31 & 8.35 & 7.39 & 6.43 & 5.47 \\
\hline & TMP ( & 14.36 & 13.46 & 12.56 & 11.66 & 10.76 & 9.85 & 8.95 & 8.05 & 7.15 & 6.25 & 5.35 \\
\hline & TMP ( & 13.86 & 13.02 & 12.17 & 11.32 & 10.47 & 9.63 & 8.78 & 7.93 & 7.08 & 6.24 & 5.39 \\
\hline & TMP ( & 13.37 & 12.64 & 11.90 & 11.17 & 44 & 9.70 & 3.97 & 8.23 & 7.50 & 5.77 & 6.03 \\
\hline & TMP $(100 \%)$ & 13.03 & 12.40 & 11.78 & 11.15 & 10.52 & 9.90 & 9.27 & 8.64 & 8.02 & 7.39 & 6.76 \\
\hline & TTP (110\%) & 12.62 & 12.03 & 11.44 & 10.85 & 10.26 & 9.67 & 9.07 & 8.48 & 7.89 & 7.30 & 6.71 \\
\hline & TTP $(120 \%)$ & 12.15 & 11.65 & 11.15 & 10.65 & 10.15 & 9.66 & 9.16 & 8.66 & 8.16 & 7.66 & 7.16 \\
\hline & TТP $(130 \%)$ & 11.85 & 11.34 & 10.84 & 10.33 & 9.82 & 9.32 & 8.81 & 8.31 & 7.80 & 7.29 & 6.79 \\
\hline & ТТР (140\%) & 11.61 & 11.19 & 10.76 & 10.33 & 9.91 & 9.48 & 9.05 & 8.62 & 8.20 & 7.77 & 7.34 \\
\hline & TTP $(150 \%)$ & 11.32 & 10.98 & 10.65 & 10.32 & 9.99 & 9.65 & 9.32 & 8.99 & 8.65 & 8.32 & 7.99 \\
\hline & $\begin{array}{l}\text { TTP }(166 \%) \\
\text { Reference scenar }\end{array}$ & 11.19 & 10.89 & 10.58 & 10.28 & 9.98 & 9.68 & 9.37 & 9.07 & 8.76 & 8.46 & 8.15 \\
\hline
\end{tabular}

Table 3. The best policies under the varying relative importance of CSC (Units: billion Yuan)

Table 3 shows that the best policy varies as the weight value of CSC increases. The larger the weight value, the lower the overload ratio of the best policy. The local government should choose the appropriate TWR policy on the basis of the relative importance of CSC compared to CEC. To be specific:

- If CSC is considered to be very unimportant, the local government should continue implementing the current TTP with the maximum overload ratio.

- If CSC is considered to be very important, then TRP is recommended.

- If CSC (CEC) is considered to be slightly more important than CEC (CSC), TMP with an overload ratio of $80 \%$ (TTP with an overload ratio of $130 \%$ ) is the best.

\section{Conclusions}

Traditionally, there has been little discussion on the sustainability of the highway freight system that considers overloaded trucking. This paper made the first effort to assess the long-term effects of TWR policies on the sustainability of the highway freight system based on the SD 
approach. The proposed model, comprising six interrelated modules, is able to reflect variations of trucking issues, including the truck traffic volume, pavement maintenance operations and trucking time, which are caused by overloaded trucks, and further calculates the changes of CEC and CSC caused by overloaded trucking. The results of the model reveal that TTP with an overload ratio of $130 \%$ is the best policy for the sustainability of the HTCT. If the varying relative importance of CSC and CEC is considered, the best policy varies as the weight value of CSC increases. The larger the weight value, the lower the overload ratio of the best policy.

This study contributes to the application of SD for highway freight systems by introducing overloaded trucking and evaluating the sustainable effects caused by overloaded trucking. The SD model helps decision makers obtain a comprehensive understanding of highway freight systems' behavior under TWR policies, and the results can help them make advisable decisions to achieve the sustainability of the systems.

One limitation of the study is that the model considers only the situation of single freight type and truck type, which is common for bulk freight trucking. Correspondingly, the results have a strong guiding value for the bulk freight trucking industry. For the more general situation in which multiple freight types exist, multiple truck types may be involved because of different shipment sizes. This situation could be solved by adding a truck fleet evolution module to the model. The other limitation is that the model considers only the trucking process, while neglecting the storage process in the port yard. The model could be improved by adding a port yard module so that the influence of the port yard storage capacity on the trucking process and on the sustainability of the highway freight system could be analyzed.

\section{Acknowledgments}

This research is supported by the Key National Natural Science Foundation of China (Grant No.71132008) and National Natural Science Foundation of China (Grant No.71473013). The authors thank Shengjun Yuan and Zhigang Qi from China Highway Consultants Co., Ltd for their useful advice and assistance during the investigation and data collection in Caofeidian District.

\section{References}

Abbas, K.A., \& Bell, M.G. (1994). System dynamics applicability to transportation modeling. Transportation Research Part A: Policy and Practice, 28(5), 373-390. http://dx.doi.org/10.1016/0965-8564(94)90022-1 
De Ceuster, G., Van Herbruggen, B., Logghe, S., \& Proost, S. (2004). TREMOVE. Report for European Commission, DG ENV, Transport \& Mobility Leuven and KU Leuven. Available online at: http://www.asser.nl/upload/eel-webroot/www/documents/TREMOVEreport.pdf (Date last access: December 10th, 2014).

De Jong, G., Gunn, H., \& Walker, W. (2004). National and international freight transport models: An overview and ideas for future development. Transport Reviews, 24(1), 103-124. http://dx.doi.org/10.1080/0144164032000080494

Dou, S., Li, X., Li, X., \& Gou, J. (2014). Study on logistics industry development policy of Beijing based on system dynamic. Journal of Industrial Engineering and Management, 7(2), 573-587. http://dx.doi.org/10.3926/jiem.1036

Fiksel, J. (2006). Sustainability and resilience: Toward a systems approach. Sustainability: Science Practice and Policy, 2(2), 14-21. Available online at: http://sspp.proquest.com/static content/vol2iss2/0608-028.fiksel-print.html (Date last access: October 12th, 2014).

Fiorello, D., Fermi, F., \& Bielanska, D. (2010). The ASTRA model for strategic assessment of transport policies. System Dynamics Review, 26(3), 283-290. http://dx.doi.org/10.1002/sdr.452

Fiorello, D., Martino, A., \& Rinaldi, M. (2002). The ASTRA-Italia model for strategic assessment of transport policies and investments. In The Twentieth International Conference of the System Dynamics Society. available online http://www.systemdynamics.org/conferences/2002/proceed/papers/Fiorell1.pdf (Date last access: December 6th, 2014).

Gao, S. (2012). A research on the development of Caofeidian port ore logistics system. Unpublished master thesis, Dalian Maritime University, Dalian, China.

Haghani, A., Lee, S.Y., \& Byun, J.H. (2003). A system dynamics approach to land use/transportation system performance modeling part I: Methodology. Journal of Advanced Transportation, 37(1), 1-41. http://dx.doi.org/10.1002/atr.5670370102

Han, J., \& Hayashi, Y. (2008). A system dynamics model of CO2 mitigation in China's inter-city passenger transport. Transportation Research Part D: Transport and Environment, 13(5), 298-305. http://dx.doi.org/10.1016/j.trd.2008.03.005

Hang, W., \& Li, X. (2010). Application of system dynamics for evaluating truck weight regulations. Transport Policy, 17(4), 240-250. http://dx.doi.org/10.1016/j.tranpol.2010.01.007 
Khan, S.U., Ayub, T., \& Qadir, A. (2014). Effect of overloaded vehicles on the performance of highway bridge girder: A case study. Procedia engineering, 77, 95-105. http://dx.doi.org/10.1016/j.proeng.2014.07.010

Li, Y. (2013). Study on road transport development model based on sustainable development theory. Unpublished doctorial dissertation, Dalian Maritime University, Dalian, China.

Maurer, H.H. (2008). Development of an integrated model for estimating emissions from freight transport. Doctoral dissertation, The University of Leeds. Available online at: http://www.its.leeds.ac.uk/peat/images/uploads/1257162332MAURER\%20PhD\%20thesis.pdf (Date last access: December 6th, 2014).

National Bureau of Statistics PRC (2013). China Statistical Yearbook 2013. Beijing, China: China Statistics Press.

Pfaffenbichler, P. (2011). Modelling with systems dynamics as a method to bridge the gap between politics, planning and science? Lessons learnt from the development of the land use and transport model MARS. Transport Reviews, 31(2), 267-289. http://dx.doi.org/10.1080/01441647.2010.534570

Pfaffenbichler, P., Emberger, G., \& Shepherd, S. (2010). A system dynamics approach to land use transport interaction modelling: The strategic model MARS and its application. System Dynamics Review, 26(3), 262-282. http://dx.doi.org/10.1002/sdr.451

Piattelli, M.L., Cuneo, M.A., Bianchi, N.P., \& Soncin, G. (2002). The control of goods transportation growth by modal share re-planning: The role of a carbon tax. System Dynamics Review, 18(1), 47-69. http://dx.doi.org/10.1002/sdr.227

Shepherd, S.P. (2014). A review of system dynamics models applied in transportation. Transport metrica B: Transport Dynamics, 2(2), 83-105. http://dx.doi.org/10.1080/21680566.2014.916236

Sun, L., \& Liu, X. (1995). General deterioration equation for pavement performance. Journal of Tongji University, 23(5), 512-518.

Tao, C.C., \& Hung, C.C. (2003). A comparative approach of the quantitative models for sustainable transportation. Journal of the Eastern Asia Society for Transportation Studies, 5, 3329-3344. Available online at: http://www.easts.info/2003journal/papers/3329.pdf (Date last access: October 20th, 2014).

Ülengin, F., Kabak, Ö., Önsel, Ş., Ülengin, B., \& Aktaş, E. (2010). A problem-structuring model for analyzing transportation-environment relationships. European Journal of Operational Research, 200(3), 844-859. http://dx.doi.org/10.1016/j.ejor.2009.01.023 
Ventana Systems, Inc. Available online at: http://vensim.com/.

Wang, W. (2003). Practical speed-flow relationship model of highway traffic-flow. Journal of Southeast University (Natural Science Edition), 4, 487-491.

$\mathrm{Xu}, \mathrm{J}$. (2008). Research on transportation cost, mechanism and management strategy of overload transportation. Unpublished doctorial dissertation, Southeast University, Nanjing, China.

Journal of Industrial Engineering and Management, 2015 (www.jiem.org)

\section{(ब)}

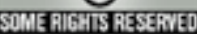

Article's contents are provided on an Attribution-Non Commercial 3.0 Creative commons license. Readers are allowed to copy, distribute and communicate article's contents, provided the author's and Journal of Industrial Engineering and Management's names are included. It must not be used for commercial purposes. To see the complete license contents, please visit http://creativecommons.org/licenses/by-nc/3.0/. 